\title{
Ultrasonic Extraction of Bioactive Compounds From Green Soybean Pods and Application in Green Soybean Milk Antioxidants Fortification
}

Noppol Leksawasdi

Chiang Mai University

Siraphat Taesuwan

Chiang Mai University

Trakul Prommajak

University of Phayao

Charin Techapun

Chiang Mai University

Rattanaporn Khonchaisri

Chiang Mai University

Nattha Sittilop

Chiang Mai University

Anek Halee

Kamphaeng Phet Rajabhat University

Kittisak Jantanasakulwong

Chiang Mai University

Suphat Phongthai

Chiang Mai University

Rojarej Nunta

Lampang Rajabhat University

Maneerat Kiadtiyot

Chiang Mai University

Arisa Saefung

Chiang Mai University

Julaluk Khemacheewakul ( $\square$ Julaluk.kh@cmu.ac.th )

Chiang Mai University

\section{Research Article}

Keywords: green soybean, ultrasonic extraction, bioactive compounds, antioxidant, Glycine max L., sustainable consumption 
Posted Date: November 17th, 2021

DOI: https://doi.org/10.21203/rs.3.rs-1048606/v1

License: (9) This work is licensed under a Creative Commons Attribution 4.0 International License. Read Full License

Version of Record: A version of this preprint was published at Foods on February 18th, 2022. See the published version at https://doi.org/10.3390/foods 11040588 . 


\section{Abstract}

Green soybean (Glycine max L.) pods (GSP) are agro-industrial waste from the production of frozen green soybean and milk. These pods contain natural antioxidants and various bioactive compounds that are still underutilized. Polyphenols and flavonoids in GSP were extracted by ultrasound techniques and used in antioxidant fortification of green soybean milk. The ultrasound extraction that yielded the highest total polyphenol content was $50 \%$ amplitude for 10 min, whereas maximum flavonoids content was obtained at $50 \%$ amplitude for 15 min. Radical scavenging activity assayed by 2,2-diphenyl-1-picryl-hydrazyl radical (DPPH) and ferric reducing antioxidant power (FRAP) methods did not differ significantly $(p>0.05)$ between the two conditions. Response surface methodology was applied to analyze an optimum ultrasonic-assisted extraction (UAE) condition of these variables. The highest desirability was found to be $50 \%$ amplitude with extraction time of $12.5 \mathrm{~min}$. Fortification of the GSP extracts (1-3\% v/v) in green soybean milk resulted in higher levels of bioactive compounds and antioxidant activity in a dosedependent manner. Procyanidins were found to be the main polyphenols in dried GSP which were present at the concentration of $104.1 \pm 2.1 \mathrm{mg} / \mathrm{g}$ dry sample, respectively. Addition of GSP extracts obtained by using an ultrasound technique to green soybean milk increased its bioactive compound content especially procyanidins as well as its antioxidant activity.

\section{Introduction}

Free radicals shorten shelf-life of food products as well as increase oxidative stress within cells, a recognized pathologic pathway of several chronic diseases ${ }^{1}$. During the past two decades, the utilization of either bioactive compounds or natural antioxidants in food products or by-products through both nonbiological ${ }^{2}$ or biological means ${ }^{3-6}$ has gained considerable interests due to the participating roles of these compounds in absorption and neutralization of free radicals thereby slowing down the autoxidation process. The favors in natural antioxidants was due not only to their biological values, but also to their economic impact, as most of them can be extracted from food by-products and under-exploited plant species ${ }^{7}$.

Legumes are an excellent source of bioactive compounds with antioxidant capacity such as flavonoids, anthocyanin and other phenolic compounds. Recent studies showed that high intake of legumes protected the human body against oxidative damage and reduced the risk of type 2 diabetes mellitus ${ }^{8}$. Green soybean (Glycine max L.) is a legume that has been shown to exhibit strong antioxidant activity ${ }^{9}$. Whole green soybean seeds contained $9.44 \pm 0.02 \mathrm{mg}$ gallic acid equivalent (GAE)/g of phenolic compounds and $8.65 \pm 0.61 \mathrm{mg}$ catechin equivalents (CAE)/g of flavonoids ${ }^{10}$, which were higher than those of black soybean ${ }^{11}$. Green soybean pods (GSP), a by-product from green soybean processing, potentially contain natural antioxidants, but research on the antioxidant capacity of these GSP are still limited.

Ultrasonic assisted extraction (UAE) has been widely used to extract antioxidants from plants. Highfrequency ultrasonic waves induce contraction and expansion cycles which subsequently cause 
cavitation, breakage of plant cell walls and infiltration of solvents into cells. The extraction rate and yield of UAE are influenced by several factors, including solvent concentration, solvent/material ratio, ultrasonication time, temperature and power ${ }^{12}$. The objectives of the present work were 1) to optimize the UAE process with water as eco-friendly solvent to obtain GSP extracts enriched in antioxidants in the classes of phenolic compounds and flavonoids; 2) to investigate antioxidant capacity of green soybean milk supplemented with GSP extracts; and 3) to identify some specific antioxidants in the GSP extracts.

\section{Materials And Methods}

Materials. Whole green soybeans (Glycine max L.) were obtained from Lanna Agro Industry Co., Ltd. (LACO), Chiang Mai, Thailand. GSPs were separated from whole bean and washed using tap water. The pods were further cut into small pieces using a stainless-steel knife and oven-dried at $60^{\circ} \mathrm{C}$ for $24 \mathrm{~h}$ in a hot air oven (Memmert UF 110, Schwabach, Germany) until moisture content decreased below $10 \%{ }^{13}$. Dried GSPs were ground to fine powder by using an electric chopper (Model DPA130, Tefal, France), packed in vacuum polyethylene bags and stored at $4^{\circ} \mathrm{C}$ before use. All chemicals used were analytical grade.

Ultrasonic-assisted extraction. Ultrasonic-Assisted Extraction (UAE) was carried out according to Sharayei et al. ${ }^{14}$ with some modifications. Specifically, $5 \mathrm{~g}$ of dried GSP powder was placed in a $250 \mathrm{~mL}$ beaker and extracted with $100 \mathrm{~mL}$ distilled water using an ultrasonic probe (VX500, USA) with a maximum power of $500 \mathrm{~W}$ at $20 \mathrm{kHz}$ frequency. Extraction was carried out for three different durations (10, 15, and $20 \mathrm{~min})$ and three different amplitudes (30,40, and $50 \%)$. The ultrasonication process was carried out in an icewater bath to prevent heating of samples. After extraction, the mixtures were centrifuged at $3000 \times \mathrm{g}$ for 15 min at $4^{\circ} \mathrm{C}$ (Nüve NF400R, Turkey), and the supernatant was filtered through filter paper (Whatman No. 1, England). The filtered extracts were collected in a centrifuge tube and kept at $-18^{\circ} \mathrm{C}$ until further analysis.

Preparation of green soybean milk. Fresh green soybean seeds $(500 \mathrm{~g})$ were soaked in 2,000 $\mathrm{mL}$ of tap water for $1 \mathrm{~min}$. The beans were then ground and blended in $1,000 \mathrm{~mL}$ of drinking water using a blending machine (HR2602, Philips, China) at medium speed until homogeneous (about $10 \mathrm{~min}$ ). The mixture was filtered using a muslin cloth to obtain green soybean milk, to which the GSP extracts were added at the concentration levels of 0 (control), 1,2 , and $3 \%(v / v)$. The green soybean milk was then boiled at $95^{\circ} \mathrm{C}$ for $20 \mathrm{~min}$ before immediately placed in an ice bath. The cooled samples were then stored at $-18^{\circ} \mathrm{C}$ until further analysis.

Determination of total phenolic compounds. Total phenolic compounds were analyzed using the Folin Ciocalteu method with some modifications ${ }^{11}$. A $500 \mu \mathrm{L}$ of properly diluted sample or standard solutions of varying concentrations were mixed with $2.5 \mathrm{~mL}$ of 1:10 Folin Ciocalteu:water solution and then thoroughly mixed. After incubation for $8 \mathrm{~min}$ at room temperature, $2 \mathrm{~mL}$ of $7.5 \%(\mathrm{w} / \mathrm{v}) \mathrm{Na}_{2} \mathrm{CO}_{3}$ solution was added, and the mixture was immediately mixed and incubated for $2 \mathrm{~h}$. Absorbance was read at 765 
$\mathrm{nm}$ on a spectrophotometer (G10S UV-Vis, Thermo Fisher Scientific, USA). Measurements were conducted in triplicates. One $\mathrm{mg} / \mathrm{mL}$ gallic acid was used as the standard, and the total phenolic compounds of the samples were expressed in mg gallic acid equivalent (GAE) per g sample (mg GAE/g).

Determination of total flavonoid content. Samples $(0.25 \mathrm{~mL})$ were mixed with $1.25 \mathrm{~mL}$ of distilled water and $75 \mu \mathrm{l}$ of $5 \% \mathrm{NaNO}_{2}$ solution and incubated for $6 \mathrm{~min}$ at room temperature. The mixture was then combined with $150 \mu \mathrm{L}$ of $10 \% \mathrm{AlCl}_{3}, 500 \mu \mathrm{L}$ of $1 \mathrm{M} \mathrm{NaOH}$ and brought to $275 \mathrm{~mL}$ with distilled water. The solution was mixed thoroughly and left for $5 \mathrm{~min}$ at room temperature. Its absorbance was recorded using a spectrophotometer at $510 \mathrm{~nm}$. Catechin equivalents (CAE) per g of sample (mg CAE/g) were used to express total flavonoid contents ${ }^{15}$.

Determination of antioxidant activity. DPPH (2,2-diphenyl-1-picryl-hydrazyl radical) solution was used to estimate antioxidant activity according to the method described by Brand-William et al. ${ }^{16}$. Briefly, $150 \mu \mathrm{L}$ of samples were mixed with $3 \mathrm{~mL}$ of $0.6 \mathrm{mM} \mathrm{DPPH}$. The mixture was incubated for $30 \mathrm{~min}$ in the dark to allow for complete reaction. Absorbance values of each sample and control (distilled water) were read using a spectrophotometer at $517 \mathrm{~nm}$. Antioxidant activity of each sample was expressed as $\mu \mathrm{mol}$ of Trolox equivalent per $\mathrm{g}$ of sample ( $\mu \mathrm{mol}$ Trolox $/ \mathrm{g}$ ). The Fe2+ chelating activity of samples were measured by the method of Sharma et al. ${ }^{17}$ with minor modifications. The ferric reducing antioxidant power (FRAP) reagent was prepared by mixing $25 \mathrm{~mL}$ of $0.3 \mathrm{M}$ acetate buffer $(\mathrm{pH} 3.6 / 22.8 \mathrm{mM}$ sodium acetate trihydrate) with $2.5 \mathrm{ml}$ of $0.01 \mathrm{M} \mathrm{2,4,6-Tripyridyl-s-Triazine} \mathrm{solution} \mathrm{and} 2.5 \mathrm{~mL}$ of $0.02 \mathrm{M} \mathrm{FeCl}_{3} .6 \mathrm{H}_{2} \mathrm{O} .150$ $\mu \mathrm{L}$ of sample or the control (methanol) was then added to $2,850 \mu \mathrm{L}$ of the FRAP reagent. The reaction mixture was incubated at room temperature in the dark for $30 \mathrm{~min}$, and absorbance was assessed at 593 $\mathrm{nm}$. Antioxidant activity of each sample was expressed as $\mu \mathrm{mol}$ Trolox $/ \mathrm{g}$.

Sensory evaluation of green soybean milk. One hundred untrained panelists (20-40 years of age) were recruited from the Division of Food Science and Technology, Faculty of Agro-industry, Chiang Mai University, Thailand. The samples were coded with a 3-digits random number and presented to the panelists. Water was provided for rinsing the mouth between samples. The panelists were asked to provide acceptance scores for color, texture, aroma, sweet taste, salt taste, and overall acceptability based on a standard nine-points hedonic scale $(9=$ like extremely, $8=$ like very much, $7=$ like moderately, $6=$ like slightly, 5 = neither like nor dislike, $4=$ dislike slightly, $3=$ dislike moderately, $2=$ dislike very much and $1=$ dislike extremely) ${ }^{18}$.

Quantification of phenolic compounds by HPLC. The phenolic compounds (procyanidins, quercetin, glycitin, daidzein, genistin, and linalool) in GSP extracts and green soybean milk were analyzed by highperformance liquid chromatography (HPLC) as previously reported ${ }^{11}$ with some modifications. Briefly, an Agilent HPLC system (Agilent Technologies, Santa Clara, California), consisting of a binary pump and a photodiode-array detector equipped with an Agilent Zorbax C18 $(4.6 \times 250 \mathrm{~mm}, 3.5 \mu \mathrm{m})$ column was employed. Mobile phase was consisted of solution A ( $0.1 \% \mathrm{v} / \mathrm{v}$ trifluoroacetic acid) and solution $B$ (pure methanol), which were used to create gradients according to the following program: 0 min, $15 \% \mathrm{~B} ; 5 \mathrm{~min}$, $25 \% \mathrm{~B} ; 9 \mathrm{~min}, 55 \% \mathrm{~B} ; 12 \mathrm{~min}, 75 \% \mathrm{~B} ; 15 \mathrm{~min}, 75 \% \mathrm{~B} ; 18 \mathrm{~min}, 15 \% \mathrm{~B}$. The flow rate was $0.8 \mathrm{~mL} / \mathrm{min}$, and 
the injection volume was $5.0 \mu \mathrm{l}$ for procyanidins, quercetin, glycitin, daidzein, and genistin. The program for linalool was $0-20 \mathrm{~min}, 85 \% \mathrm{~B}$. The detection wavelength was set at $260 \mathrm{~nm}$ for procyanidins, quercetin, glycitin, daidzein and genistin, and at 210 for linalool. The result was expressed as $\mathrm{mg}$ of procyanidins, quercetin, glycitin, daidzein, genistin, and linalool equivalent per $100 \mathrm{~g}$ of sample.

Statistical analysis. Amplitude and exposure time variables were analyzed using two-ways analysis of variance for each of the four measures of ultrasonic performance. Comparison among different proportions of GSP supplements in green soybean milk on the antioxidant and sensory characteristic were analyzed using one-way analysis of variance. Significant difference $(P \leq 0.05)$ among samples were followed by Duncan's new multiple range post-hoc analysis. All above analyses were conducted using SPSS for Window version 16. Data were reported as mean values \pm standard deviation. Response surface methodology was applied to analyze an optimum UAE condition using Design Expert version 6.0.11 (Stat-Ease, MN).

\section{Results And Discussion}

Bioactive components. Total phenolic contents varied from 85.9 to $107 \mathrm{mg} \mathrm{GAE} / \mathrm{g}$ across different ultrasonic processing conditions (Table 1). Amplitude had a significant effect $(P \leq 0.05)$ on total phenolic content during 10 to $15 \mathrm{~min}$ extraction time. The highest total phenolic content of $107 \pm 1.0 \mathrm{mg} \mathrm{GAE} / \mathrm{g}$ was obtained using the highest amplitude (50\%) for $10 \mathrm{~min}$. In contrast, the $30 \%$ and $40 \%$ amplitude (vs. $50 \%$ ) for 10 min yielded significantly lower phenolic content ( $85.9 \pm 1.7$ and $91.5 \pm 2.2 \mathrm{mg} \mathrm{GAE} / \mathrm{g}$ respectively). A higher amplitude creates higher thermal energy to break the plant cellular structure. Increased permeability of cell walls and membranes and the breakdown of secondary metabolites from matrix interactions (polyphenols with lipoproteins) caused enhancement of polyphenols solubility and mass transfer. Thus, a higher ultrasonic amplitude increased extraction efficiency and yielded greater amounts of bioactive compounds ${ }^{19,20}$. In this study, increased extraction time from 10 to 20 min at $50 \%$ amplitude resulted in lower phenolic content. Longer exposure time could increase solvent temperature beyond optimal levels, resulting in the degradation of thermo-sensitive compounds presented in the GSP samples. Evidently, the extraction condition of $10 \mathrm{~min}$ at $50 \%$ amplitude was deemed optimal for phenolic content.

Flavonoids have been shown to improve blood lipid profiles, enhance immunity, and have antioxidant, antibacterial and antitumor properties ${ }^{21}$. Table 1 shows a significant $(P \leq 0.05)$ time $\times$ amplitude interaction. Increasing extraction time from 10 to 20 min increased flavonoid content only at $30 \%$ amplitude, while at $40 \%$ and $50 \%$ amplitude, total flavonoid increased up to $15 \mathrm{~min}$ before declining at 20 min. When considering the effect of amplitude, a higher amplitude resulted in a higher flavonoid content only in the 10 -min extraction groups. In contrast, the $50 \%$ amplitude mitigated flavonoid content significantly $(P \leq 0.05)$ in the 20-min extraction groups. Loss of flavonoids at higher amplitude or longer extraction time was due to overheating by the ultrasound treatment, which especially affected the heatsensitive flavonoids ${ }^{22}$. Moreover, flavonoids (e.g., rutin) were more sensitive to thermal degradation than phenolic acids. The concentration of rutin from olive leaves using ultrasound-assisted extraction was 
$2.11 \pm 0.1 \mathrm{mg} / \mathrm{g}$ during longer extraction time of $21 \mathrm{~min}$ which was lower than the extraction time of 7 $\min (2.22 \pm 0.1 \mathrm{mg} / \mathrm{g}){ }^{23}$. From the results, the total flavonoid contents of the extract increased with increasing time from 10 to $15 \mathrm{~min}$, after which the values reduced slightly. According to Bi et al. ${ }^{24}$, the gradual increase in the bioactivity of the extract with time may be attributed to the fact that polyphenols, and other bioactive compounds were still bound within the cell matrices during the early stage of extraction. The sufficient time was thus required to allow for their release. The subsequent decrease in bioactivity might be due to the longer time of exposure to ultrasonic conditions, inducing the degradation or oxidation of these bioactive compounds. Based on these findings, the extraction condition of $15 \mathrm{~min}$ at $50 \%$ amplitude was deemed optimal for flavonoid content. Therefore, the suitable range of extraction time for the subsequent optimization process was chosen to be from 10 to $15 \mathrm{~min}$.

Table 1. Total phenolic (mg GAE/g) and flavonoid (mg CAE/g) content and antioxidant activity based on DPPH and FRAP (\%) of ultrasound-assisted green soybean pod extracts as a function of time and the ultrasonic amplitude level.

\begin{tabular}{|c|c|c|c|c|c|}
\hline \multirow[t]{2}{*}{$\begin{array}{l}\text { Time } \\
(\text { min) }\end{array}$} & \multirow[t]{2}{*}{$\begin{array}{l}\text { Amplitude } \\
\text { (\%) }\end{array}$} & \multirow{2}{*}{$\begin{array}{l}\text { Total phenolic } \\
\text { content } \\
\text { (mg GAE/g) }\end{array}$} & \multirow{2}{*}{$\begin{array}{l}\text { Total flavonoid } \\
\text { content } \\
\text { (mg CAE/g) }\end{array}$} & \multicolumn{2}{|c|}{$\begin{array}{l}\text { Antioxidant activities } \\
(\mu \mathrm{mol} \text { Trolox } / \mathrm{g})\end{array}$} \\
\hline & & & & DPPH & FRAP \\
\hline \multirow[t]{3}{*}{10} & 30 & $85.9 \pm 1.7^{d}$ & $6.19 \pm 0.2^{e}$ & $24.4 \pm 0.1^{a}$ & $\begin{array}{l}45.4 \pm 0.1 \\
a\end{array}$ \\
\hline & 40 & $91.5 \pm 2.2^{c}$ & $6.56 \pm 0.7^{d}$ & $24.3 \pm 0.3^{a b}$ & $\begin{array}{l}45.3 \pm 0.1 \\
\mathrm{a}\end{array}$ \\
\hline & 50 & $107 \pm 1.0^{a}$ & $7.75 \pm 0.9^{c}$ & $\begin{array}{l}24.1 \pm 0.3 \\
a b c\end{array}$ & $\begin{array}{l}45.6 \pm 0.1 \\
\mathrm{a}\end{array}$ \\
\hline \multirow[t]{3}{*}{15} & 30 & $90.9 \pm 2.2^{c}$ & $8.50 \pm 0.3^{a b c}$ & $\begin{array}{l}23.6 \pm 0.3 \\
b c d\end{array}$ & $\begin{array}{l}45.4 \pm 0.1 \\
a\end{array}$ \\
\hline & 40 & $93.2 \pm 2.0^{c}$ & $8.69 \pm 0.6^{a b}$ & $\begin{array}{l}23.6 \pm 0.7 \\
\text { abcd }\end{array}$ & $\begin{array}{l}45.5 \pm 0.1 \\
\text { a }\end{array}$ \\
\hline & 50 & $102.7 \pm 1.0^{b}$ & $8.94 \pm 0.3^{a}$ & $\begin{array}{l}24.1 \pm 0.1 \\
a b c\end{array}$ & $\begin{array}{l}45.4 \pm 0.1 \\
\text { a }\end{array}$ \\
\hline \multirow[t]{3}{*}{20} & 30 & $90.6 \pm 2.0^{c}$ & $8.81 \pm 0.3^{a b}$ & $23.3 \pm 0.3^{d}$ & $\begin{array}{l}45.4 \pm 0.1 \\
\text { a }\end{array}$ \\
\hline & 40 & $91.3 \pm 2.3^{c}$ & $7.94 \pm 0.9 b c$ & $23.4 \pm 0.4^{c d}$ & $\begin{array}{l}45.5 \pm 0.1 \\
a\end{array}$ \\
\hline & 50 & $90.2 \pm 2.3^{c}$ & $5.50 \pm 0.5^{e}$ & $\begin{array}{l}24.0 \pm 0.9 \\
a b c d\end{array}$ & $\begin{array}{l}45.5 \pm 0.1 \\
\mathrm{a}\end{array}$ \\
\hline
\end{tabular}


Data are expressed as means \pm standard deviation $(n=3)$. Different letters (a-e) in the same column represent statistically significant difference $(p \leq 0.05)$. DPPH = 2,2-diphenyl-1-picryl-hydrazyl radical; FRAP = ferric reducing antioxidant power.

Antioxidant activity. DPPH assay had been used widely and was a popular technique to assess the free radical scavenging activity of different plant extracts. DPPH free radical reduction was determined by the decrease in its absorption at $517 \mathrm{~nm}$ when the color of the DPPH assay solution changed from purple to light yellow. The scavenging potential of plant extract antioxidants corresponds to the degree of the discoloration ${ }^{25}$. The effect of different conditions on DPPH radical scavenging activity of GSP extracts (Table 1) revealed high antioxidant activity of all sample extracts in the range of $23.3-24.4 \mu \mathrm{mol}$ Trolox/g. Moreover, the $10 \mathrm{~min}, 30 \%$ amplitude has the highest DPPH scavenging activity $(24.4 \pm 0.1$ $\mu \mathrm{mol}$ Trolox/g). Amplitude did not significantly influence DPPH activity at any extraction time, while longer extraction time seemed to decrease DPPH activity at the $30 \%$ and the $40 \%$ amplitude. It was observed that the longer of the extraction time than $15 \mathrm{~min}$ had significant influence on the antioxidant extraction $(P \leq 0.05)$. This might be due to the small particle diameter of the green soybean pod powder, as the result indicated that 10-15 min was sufficient to reach the maximum efficiency of the extraction. These results were consistent with an earlier report by Wang et al. ${ }^{26}$, who found no increase in total content of phenolic and flavonoid with extraction time beyond $15 \mathrm{~min}$ when extracting blueberry leaves using ultrasonic extraction. Moreover, Ćujić et al. ${ }^{27}$ reported no difference between the total phenolic content from dried chokeberries obtained after 30 and 60 min ultrasonic extraction in $50 \%$ ethanol. It was noteworthy that longer extraction time in water could lead to the decrease in antioxidant activity. It was evident that with some plant materials, excessive extraction duration in water may cause degradation of some target compounds resulting in reduced contents. In contrast to the DPPH results, FRAP antioxidant activity did not differ $(\mathrm{p} \otimes 0.05)$ between treatment conditions. The highest FRAP activity $(45.6 \pm 0.1 \mu \mathrm{mol}$ Trolox/g) was exhibited by samples extracted with $50 \%$ amplitude with extraction time of 10 min. Moreover, the variation trend of FRAP values was consistent with the total phenolic contents. These results were in accordance with Hassan et al. ${ }^{28}$ who observed that phenolics contents of brown seaweed extract using UAE with a working frequency fixed at $42 \mathrm{kHz}$ and a power of $100 \mathrm{~W}$ had a close correlation with FRAP antioxidant. In addition, there was no significant difference $(p<0.05)$ of total phenolic contents and FRAP antioxidant power of brown seaweeds extract for extraction time of 20 min (4.23 \pm $0.1 \mathrm{mg} \mathrm{GAE} / \mathrm{g}$ and $4.83 \pm 0.1 \%)$ and $30 \mathrm{~min}(4.34 \pm 0.2 \mathrm{mg} \mathrm{GAE} / \mathrm{g}$ and $5.09 \pm 0.1 \%)$, respectively.

The correlation between UAE conditions and response variables could be fit with quadratic and linear models, as follows:

Total phenolics $=28.63+7.31 T+0.13 A-0.11 T^{2}+0.03 A^{2}-0.11 T A\left(p<0.0001, R^{2}=0.90\right)$

Total flavonoids $=-20.17+2.93 \mathrm{~T}+0.34 \mathrm{~A}-0.06 \mathrm{~T}^{2}-0.02 \mathrm{TA}\left(\mathrm{p}<0.0001, \mathrm{R}^{2}=0.77\right)$

$\mathrm{DPPH}=27.21-0.26 \mathrm{~T}-0.06 \mathrm{~A}+4.86 \mathrm{TA}\left(\mathrm{p}=0.0005, \mathrm{R}^{2}=0.42\right)$ 
FRAP $=45.14+9.22 T+3.56 A\left(p=0.0102, R^{2}=0.24\right)$

where $\mathrm{T}$ was extraction temperature and $\mathrm{A}$ was ultrasonic amplitude. However, the $\mathrm{R}^{2}$ for for DPPH and FRAP models were less than 0.5 . Therefore, optimization criteria was set for maximum total phenolics and total flavonoids. The response surfaces of these variables are shown in Figure 1. The highest values occurred with $50 \%$ amplitude and extraction time of $12.5 \mathrm{~min}$ which yielded the total phenolics value of $104 \mathrm{mg} \mathrm{GAE} / \mathrm{g}$ and total flavonoids of $8.61 \mathrm{mg} \mathrm{CAE} / \mathrm{g}$.

\section{Evaluation of antioxidant and sensory properties of green soybean milk fortified with GSP}

Extracts. Bioactive compounds comprised an excellent pool of molecules for the production of nutraceuticals, functional foods, and food additives ${ }^{29}$. The pod of green soybean waste was collected from shelling process before the seed was grounded for milk production. The GSP extracts produced from the optimized UAE were used as natural antioxidants in term of food additive for improving the oxidative stability in green soybean milk. Phenolic and flavonoid contents as well as antioxidant activity of GSP-fortified green soybean milk are shown in Table 2. Among all samples, the $3 \%$ fortified milk sample had the highest phenolic ( $136 \pm 0.5 \mathrm{mg} \mathrm{GAE} / \mathrm{g}$ ) and flavonoid (109 $\pm 0.5 \mathrm{mg} \mathrm{GAE} / \mathrm{g}$ ) content and the highest DPPH (176 $\pm 1.9 \mu \mathrm{mol}$ Trolox/g) and FRAP (248 $\pm 0.3 \mu \mathrm{mol}$ Trolox/g) antioxidant activity. In a similar study, Dabija et al. ${ }^{30}$ revealed that the fortification of yogurt with hawthorn (Crataegus monogyna) extracted in the increasing concentration levels $(0.25,0.50,0.75$, and $1 \%(\mathrm{w} / \mathrm{w}))$ could promote the higher total phenolic content $(3.46,3.88,4.22,4.34 \mathrm{mg} \mathrm{GAE} / \mathrm{mL}$, respectively) and DPPH activity $\left(19.23,21.60,32.02\right.$, and $33.38 \%$, respectively). Lee et al. ${ }^{31}$ also found that the increase in concentration level of Inula britannica flower extract for cheese fortification from 0.25 to $1.0 \%(\mathrm{w} / \mathrm{v})$ caused an increase of total phenolic content and DPPH of from 54.8 to $70.8 \mathrm{mg}$ of GAE/g and from 53.3 to $79.1 \%$, respectively. It was thus evident that the bioactive compounds and antioxidant activities of green soybean milk could be enhanced by the pod extracted fortification compared to milk alone.

Table 2. The content of phenolic and flavonoid, antioxidant activities of green soybean milk fortified with pod extracted. 


\begin{tabular}{|c|c|c|c|c|}
\hline \multirow[t]{2}{*}{$\begin{array}{l}\text { Pod extracted in green soybean } \\
\text { milk (\%) }\end{array}$} & \multirow[t]{2}{*}{$\begin{array}{l}\text { Total phenolic } \\
\text { content } \\
\text { (mg GAE/g) }\end{array}$} & \multirow[t]{2}{*}{$\begin{array}{l}\text { Total flavonoid } \\
\text { content } \\
(\mathrm{mg} \mathrm{CAE} / \mathrm{g})\end{array}$} & \multicolumn{2}{|c|}{$\begin{array}{l}\text { Antioxidant } \\
\text { activities } \\
(\mu \mathrm{mol} \text { Trolox/g) }\end{array}$} \\
\hline & & & DPPH & FRAP \\
\hline 0 (Control) & $81.3 \pm 0.8^{c}$ & $42.0 \pm 0.9^{c}$ & $\begin{array}{l}53.2 \pm \\
1.2^{d}\end{array}$ & $\begin{array}{l}239 \pm \\
0.4^{b}\end{array}$ \\
\hline 1 & $115 \pm 2.5^{b}$ & $85.3 \pm 1.2^{b}$ & $\begin{array}{l}125 \pm \\
1.1^{\mathrm{c}}\end{array}$ & $\begin{array}{l}240 \pm \\
0.2^{\mathrm{b}}\end{array}$ \\
\hline 2 & $114 \pm 2.8^{b}$ & $85.7 \pm 1.1^{b}$ & $\begin{array}{l}132 \pm \\
1.9^{\mathrm{b}}\end{array}$ & $\begin{array}{l}240 \pm \\
0.1^{b}\end{array}$ \\
\hline 3 & $136 \pm 0.5^{\mathrm{a}}$ & $109 \pm 0.5^{a}$ & $\begin{array}{l}176 \pm \\
1.9^{\mathrm{a}}\end{array}$ & $\begin{array}{l}248 \pm \\
0.3^{\mathrm{a}}\end{array}$ \\
\hline
\end{tabular}

Data are expressed as means \pm standard deviation $(n=3)$. Different letters $(a-c)$ in the same column represent statistically significant difference $(p \leq 0.05)$. NS = non-significant.

Sensory evaluation of fortified green soybean milk was conducted by 100 untrained panelists on a 9point structured scale, with 9 being the best and 1 the worst quality. All sensory attributes were in the range of 5 - 8 indicating that all formulae were at least moderately acceptable. Addition of $3 \%(\mathrm{v} / \mathrm{v}) \mathrm{GSP}$ extracts resulted in higher aroma $(6.24 \pm 1.6)$, sweetness $(5.88 \pm 1.6)$ and saltiness $(5.94 \pm 1.7)$ ratings, and a lower color $(7.28 \pm 1.2)$ rating, compared to the control formula (Table 3$)$. The lower appearance rating may be attributed to the intense green color of the product due to addition of the GSP extract, which increased the green color, but reduced the luminosity of the milk. More intense green color was not generally well accepted by consumer. Tamer et al. ${ }^{32}$ reported that lemonade with $5 \%(\mathrm{v} / \mathrm{v})$ green tea was rated lower in terms of color compared to control samples $(0 \%)$. In addition, Farhan et al. ${ }^{33}$ found that yogurt fortified with mint leave extracts had a lower color score than the control. Although color was directly related to consumer acceptability of the product ${ }^{34}$, overall acceptability scores did not differ between the $3 \%$ formula and the control. In fact, the color of the $3 \%(\mathrm{v} / \mathrm{v})$ GSP-fortified milk, which was supposedly the greenest, was accepted equally to the color of the control. The panelists preferred the $3 \%$ formula the most, even more than the $2 \%$ formula. Based on the favorable sensory and antioxidant results, the $3 \%(\mathrm{v} / \mathrm{v})$ GSP-fortified milk was selected for quantification of phytochemicals by HPLC.

Table 3. Sensory analysis of green soybean milk fortified with GSP extracts. Product preference was evaluated using a 9-point hedonic scale. 


\begin{tabular}{|lllllll|}
\hline $\begin{array}{l}\text { Green soybean pod } \\
\text { fortification (\%) }\end{array}$ & Color & Texture & Aroma & Sweetness & Saltiness & Overall \\
\hline 0 (Control) & $7.39 \pm$ & $6.75 \pm$ & $6.01 \pm$ & $5.74 \pm$ & $5.34 \pm$ & $6.46 \pm$ \\
& $1.2^{\mathrm{a}}$ & $1.5^{\mathrm{a}}$ & $2.0^{\mathrm{a}}$ & $1.8^{\mathrm{b}}$ & $2.0^{\mathrm{b}}$ & $1.7^{\mathrm{ab}}$ \\
\hline 1 & $7.24 \pm$ & $6.67 \pm$ & $6.20 \pm$ & $6.07 \pm$ & $5.90 \pm$ & $6.46 \pm$ \\
& $1.1^{\mathrm{ab}}$ & $1.5^{\mathrm{a}}$ & $1.6^{\mathrm{a}}$ & $1.7^{\mathrm{ab}}$ & $1.7^{\mathrm{a}}$ & $1.5^{\mathrm{ab}}$ \\
\hline 2 & $7.16 \pm$ & $6.37 \pm$ & $6.01 \pm$ & $6.12 \pm$ & $5.76 \pm$ & $6.17 \pm$ \\
& $1.4^{\mathrm{b}}$ & $1.5^{\mathrm{b}}$ & $1.7^{\mathrm{a}}$ & $1.7^{\mathrm{a}}$ & $1.8^{\mathrm{a}}$ & $1.5^{\mathrm{b}}$ \\
\hline 3 & $7.28 \pm$ & $6.96 \pm$ & $6.24 \pm$ & $5.88 \pm$ & $5.94 \pm$ & $6.54 \pm$ \\
& $1.2^{\mathrm{ab}}$ & $1.7^{\mathrm{a}}$ & $1.6^{\mathrm{a}}$ & $1.6^{\mathrm{ab}}$ & $1.7^{\mathrm{a}}$ & $1.4^{\mathrm{a}}$ \\
\hline
\end{tabular}

Data are expressed as means \pm standard deviation $(n=100)$. Different letters $(a-c)$ in the same column represent statistically significant difference $(p \leq 0.05)$. NS $=$ Non-significant.

Quantitative analysis of phytochemicals composition. Quantification of phytochemical contents (procyanidins, quercetin, glycitein, daidzein, genistin, and linalool) in GSP extracts and green soybean milk with and without addition of GSP were determined using HPLC (Figure 2). The most abundant phytochemicals in GSP were procyanidins $(0.72 \pm 0.01 \mathrm{mg} / 100 \mathrm{~g})$ followed by linalool $(0.69 \pm 0.11$ $\mathrm{mg} / 100 \mathrm{~g})$ and quercetin $(0.47 \pm 0.02 \mathrm{mg} / 100 \mathrm{~g})$. The procyanidin content in the GSP extracts in the present study was higher than lentils $(0.5 \mathrm{mg} / 100 \mathrm{~g}){ }^{35}$. Compared to GSP, greater amounts of phytochemicals were observed in green soybean seed, especially procyanidins $(3.89 \pm 0.04 \mathrm{mg} / 100 \mathrm{~g})$, linalool $(2.79 \pm 0.01 \mathrm{mg} / 100 \mathrm{~g})$, glycitein $(1.36 \pm 0.01 \mathrm{mg} / 100 \mathrm{~g})$ and quercetin $(1.14 \pm 0.01 \mathrm{mg} / 100 \mathrm{~g})$.

These results were not surprising because bean seeds are nutrient- and antioxidant-rich ${ }^{36}$. Hence, the green soybean milk had more content of these phytochemical group than the pod extracted sample. Nonetheless, the GSP extracts contained greater amounts of daidzein and genistein than the green soybean milk, according to Avanza et al. ${ }^{8}$ who compared the content of polyphenols from cowpea seeds and pods in the extracts of water by pressurized liquid extraction. Although the result showed the higher polyphenol content in pods than in seeds, there were remarkable differences between the analyzed of flavonoids group. Cowpea seed extracts exhibited higher content on quercetin, procyanidin, and other tetrahydroxylated flavonoids than pod extracts. Regarding pod extract, the presence of gallic, ferulic acids, and o-hydroxybenzoic acid were in greater abundant. These results might be due to the different groups of polyphenol compounds (flavonoid and phenolic acid) existed naturally in legume pods and seeds. Procyanidins were a subclass of flavonoids found in commonly consumed foods such as fruits, vegetables, legumes, grains, and nuts, which had attracted increasing attention due to their potential health benefits ${ }^{37}$. In addition to antioxidant properties, procyanidins had been reported to exhibit anticancer ${ }^{38}$, anti-infectious, anti-inflammatory, cardioprotective, antimicrobial, antiviral, antimutagenic, wounding healing, antihyperglycemic as well as anti-allergic activities ${ }^{39}$. Moreover, polyphenol compounds like quercetin were reported to have neuroprotective properties attributed to their inhibiting 
activity against enzyme acetylcholinesterase ${ }^{40}$. Other polyphenols, such as genistein, daidzein, and glycitein were main phytoestrogens in the form of isoflavones. Phytoestrogens can also suppress the clinical symptoms of menopause caused by a decrease in the production of endogenous estrogen. Several studies had proven the protective effects of phytoestrogens on cardiovascular disease which could decrease total cholesterol and improve heart function ${ }^{41}$. Linalool was present at rather high concentration levels in pod extract. This kind of phytochemical was acyclic monoterpene which was an important odorous constituent in a series of plant aromas. Linalool and linalool-rich essential oils were also known to exhibit various biological activities such as antimicrobial, anti-inflammatory, anticancer, anti-oxidant properties. In fact, several in vivo studies have confirmed various effects of linalool on the central nervous system ${ }^{42}$. Fortification of green soybean milk with GSP extracts enhanced both the antioxidant activity and the phytochemical content and variety of the products, thus its increasing nutritional values.

\section{Conclusions}

The optimal conditions for UAE of GSP extract are 50\% amplitude for $12.5 \mathrm{~min}$. Green soybean milk samples containing 3\% GSP extracts have the highest phenolic and flavonoid content, antioxidant activity, and overall acceptability compared to the control formula. Procyanidins was found the highest concentration level from green soy bean pod extract among five phytochemicals analysis. Study results suggest that GSP extracts are a potential source of natural antioxidants, pharmaceutical, and functional ingredients in food industries.

\section{Declarations}

\section{Acknowledgments}

The authors gratefully acknowledge the green soybean support from Lanna Agro Industry for this project. The authors would like to thank Chiang Mai University (CMU), Agro-Bio-Circular-Green (Agro-BCG) and Bioprocess Research Cluster (BRC) for in-kind assistance.

\section{Author Contributions}

J.K. designed the study. J.K., R.K., N.S., M.K., A.S. performed the experiments, collected, and analyzed the data. J.K., N.L., S.T., T.P. wrote the initial draft of the manuscript. S.T., N.L., S.P., K.J., C.T., A.H., R.J. revised the manuscript. J.K., N.L., S.T. wrote the final version of the manuscript. All authors reviewed the final version of the manuscript.

\section{Funding}

The presented work was funded by the Talent Mobility project by the National Science Technology and Innovation Policy Office (STI) and the Office of the Higher Education Commission (OHEC) (Grant Number: $\mathrm{NCH} 128)$. 


\section{Competing interests}

The authors report no conflicts of interest. The authors alone are responsible for the content and writing of the paper.

\section{References}

1. Lourenço, S. C., Moldão-Martins, M. \& Alves, V. D. Antioxidants of natural plant origins: from sources to food industry applications. Molecules. 24, 1-25 (2019).

2. Seesuriyachan, P. et al. Improvement in efficiency of lignin degradation by Fenton reaction using synergistic catalytic action. Ecol. Eng. 85, 283-287 (2015).

3. Leksawasdi, N., Breuer, M., Hauer, B., Rosche, B. \& Rogers, P. L. Kinetics of pyruvate decarboxylase deactivation by benzaldehyde. Biocatal. Biotransformation 21, 315-320 (2003).

4. Leksawasdi, N. et al. Kinetic analysis and modelling of enzymatic (R)-phenylacetylcarbinol batch biotransformation process. J. Biotechnol. 111, 179-189 (2004).

5. Takenaka, S. et al. Characterization of the native form and the carboxy-terminally truncated halotolerant form of a-amylases from Bacillus subtilis strain FP-133. J. Basic Microbiol. 55, 780-789 (2015).

6. Zhang, N. et al. Cell permeability and nuclear DNA staining by propidium iodide in basidiomycetous yeasts. Appl. Microbiol. Biotechnol. 102, 4183-4191 (2018).

7. Rotili, M. C. C. et al. Bioactive compounds, antioxidant and physic-chemical characteristics of the dovyalis fruit Maria Cristina. Acta Sci. - Agron. 40, 1-8 (2018).

8. Avanza, M. V., Álvarez-Rivera, G., Cifuentes, A., Mendiola, J. A. \& Ibáñez, E. Phytochemical and functional characterization of phenolic compounds from cowpea (Vigna unguiculata (L.) Walp.) obtained by green extraction technologies. Agronomy 11, 162-180 (2021).

9. Mai, H. N. D. et al. Quality evaluation of butter cake prepared by substitution of wheat flour with green soybean (Glycine Max L.) okara. https://doi.org/10.1080/15428052.2021.1978363 (2021).

10. Rani, S., Singh, R., Kamble, D. B., Upadhyay, A. \& Kaur, B. P. Structural and quality evaluation of soy enriched functional noodles. Food Biosci. 32, 1-8 (2019).

11. Zhou, R., Cai, W. \& Xu, B. Phytochemical profiles of black and yellow soybeans as affected by roasting. Int. J. Food Prop. 20, 3179-3190 (2017).

12. Tang, W., Li, S., Wang, M. \& Wang, B. Ultrasound-assisted extraction of four groups of Osmanthus fragrans fruit: optimization, UPLC-Orbitrap-MS/MS characterization and anti-inflammatory activity evaluation. Arab. J. Chem. 14(4), 1-12 (2021).

13. Khemacheewakul, J. et al. Production and storage stability of antioxidant fiber from pigeon pea (Cajanus cajan) pod. J. Microbiol. Biotechnol. Food Sci. 9, 293-297 (2019).

14. Sharayei, P., Azarpazhooh, E., Zomorodi, S. \& Ramaswamy, H. S. Ultrasound assisted extraction of bioactive compounds from pomegranate (Punica granatum L.) peel. LWT 101, 342-350 (2019). 
15. Yusnawan, E. Effects of different extraction methods on total phenolic content and antioxidant activity in soybean cultivars. in IOP Conference Series: Earth and Environmental Science 102, 111 (2018).

16. Brand-Williams, W., Cuvelier, M. E. \& Berset, C. Use of a free radical method to evaluate antioxidant activity. LWT - Food Sci. Technol. 28(1), 25-30 (1995).

17. Sharma, S., Singh, A. \& Singh, B. Characterization of in vitro antioxidant activity, bioactive components, and nutrient digestibility in pigeon pea (Cajanus cajan) as influenced by germination time and temperature. J. Food Biochem. 43(2), 1-13 (2019).

18. Al-Nabulsi, A. et al. Sensory evaluation of flavored soy milk-based yogurt: a comparison between Jordanian and Malaysian consumers. J. Food Eng. 4, 27-35 (2014).

19. Cabrera-Trujillo, M. A., Sotelo-Díaz, L. I. \& Quintanilla-Carvajal, M. X. Effect of amplitude and pulse in low frequency ultrasound on oil/water emulsions. DYNA 83, 63-68 (2016).

20. Jovanović, A. A. et al. Optimization of the extraction process of polyphenols from Thymus serpyllum L. herb using maceration, heat- and ultrasound-assisted techniques. Sep. Purif. Technol. 179, 369380 (2017).

21. Tungmunnithum, D., Thongboonyou, A., Pholboon, A. \& Yangsabai, A. Flavonoids and other phenolic compounds from medicinal plants for pharmaceutical and medical aspects: an overview. Medicines 5(3), 93-109 (2018).

22. Chimsook, T. \& Wannalangka, W. Effect of microwave pretreatment on extraction yield and quality of catfish oil in Northern Thailand. MATEC Web Conf. 35, 1-5 (2015).

23. Dobrinčić, A. et al. Comparison of different extraction methods for the recovery of olive leaves polyphenols. Processes 8(9), 1-13 (2020).

24. Bi, Y., Lu, Y., Yu, H. \& Luo, L. Optimization of ultrasonic-assisted extraction of bioactive compounds from Sargassum henslowianum using response surface methodology. Pharmacogn. Mag. 15(60), 156-163 (2019).

25. Safdar, M. N. et al. Extraction and quantification of polyphenols from kinnow (Citrus reticulate L.) peel using ultrasound and maceration techniques. J. Food Drug Anal. 25, 488-500 (2017).

26. Wang, T. et al. Ultrasound-negative pressure cavitation extraction of phenolic compounds from blueberry leaves and evaluation of its DPPH radical scavenging activity. Food Bioprod. Process. 108, 69-80 (2018).

27. Ćujić, N. et al. Optimization of polyphenols extraction from dried chokeberry using maceration as traditional technique. Food Chem. 194, 135-142 (2016).

28. Hassan, I. H., Pham, H. N. T. \& Nguyen, T. H. Optimization of ultrasound-assisted extraction conditions for phenolics, antioxidant, and tyrosinase inhibitory activities of Vietnamese brown seaweed (Padina australis). J. Food Process. Preserv. 45(3) 1-15 (2021).

29. Gil-Chávez, G. J. et al. Technologies for extraction and production of bioactive compounds to be used as nutraceuticals and food ingredients: an overview. Compr. Rev. Food Sci. Food Saf. 12, 5-23 (2013). 
30. Dabija, A., Codină, G. G., Ropciuc, S., Gâtlan, A. M. \& Rusu, L. Assessment of the antioxidant activity and quality attributes of yogurt enhanced with wild herbs extracts. J. Food Qual. 4, 1-12 (2018).

31. Lee, N. K., Jeewanthi, R. K. C., Park, E. H. \& Paik, H. D. Short communication: Physicochemical and antioxidant properties of Cheddar-type cheese fortified with Inula britannica extract. J. Dairy Sci. 99, 83-88 (2016).

32. Tamer, C. E., Yekeler, F. Z., Çopur, Ö. U., İncedayi, B. \& Suna, S. A study of fortification of lemonade with herbal extracts. Food Sci. Technol. 37, 45-51 (2017).

33. Farhan, A., Al-Zobaidy, H. N. \& Al-Quraishi, M. F. Fortification of thick yogurt with mint (Mentha spicata L.) leaves extract. Biochem. Cell. Arch. 20, 1679-1684 (2020).

34. Itthivadhanapong, P. \& Sangnark, A. Effects of substitution of black glutinous rice flour for wheat flour on batter and cake properties. Int. Food Res. J. 23(3),1190-1198 (2016).

35. Smitha, M.S., Singh, S. \& Singh, R. Microbial Biotransformation: a process for chemical alterations. J. Bacteriol. Mycol. Open Access 4(2), 47-51 (2017).

36. Weidner, S., Król, A., Karamać, M. \& Amarowicz, R. Phenolic compounds and the antioxidant properties in seeds of green- and yellow-podded bean (Phaseolus vulgaris L.) varieties. CYTA J Food $16,373-380$ (2018).

37. Rue, E. A., Rush, M. D. \& Breemen, R. B. van. Procyanidins: a comprehensive review encompassing structure elucidation via mass spectrometry. Phytochem. Rev. 17(1), 1-16 (2018).

38. Li, H. Z., Zhang, Z. J., Hou, T. Y., Li, X. J. \& Chen, T. Optimization of ultrasound-assisted hexane extraction of perilla oil using response surface methodology. Ind. Crops Prod. 76, 18-24 (2015).

39. H, Z., Y, C., X, L. \& Y, D. Protective effect of procyanidins extracted from the lotus seedpod on immune function injury induced by extremely low frequency electromagnetic field. Biomed. Pharmacother. $\mathbf{8 2}$, 364-372 (2016).

40. Khan, H., Marya, Amin, S., Kamal, M. A. \& Patel, S. Flavonoids as acetylcholinesterase inhibitors: current therapeutic standing and future prospects. Biomed. Pharmacother. 101, 860-870 (2018).

41. Desmawati, D. \& Sulastri, D. Phytoestrogens and their health effect. Open Access Maced. J. Med. Sci. 7(3), 495-499 (2019).

42. Pereira, I., Severino, P., Santos, A. C., Silva, A. M. \& Souto, E. B. Linalool bioactive properties and potential applicability in drug delivery systems. Colloids Surfaces B Biointerfaces $171,566-578$ (2018).

\section{Figures}



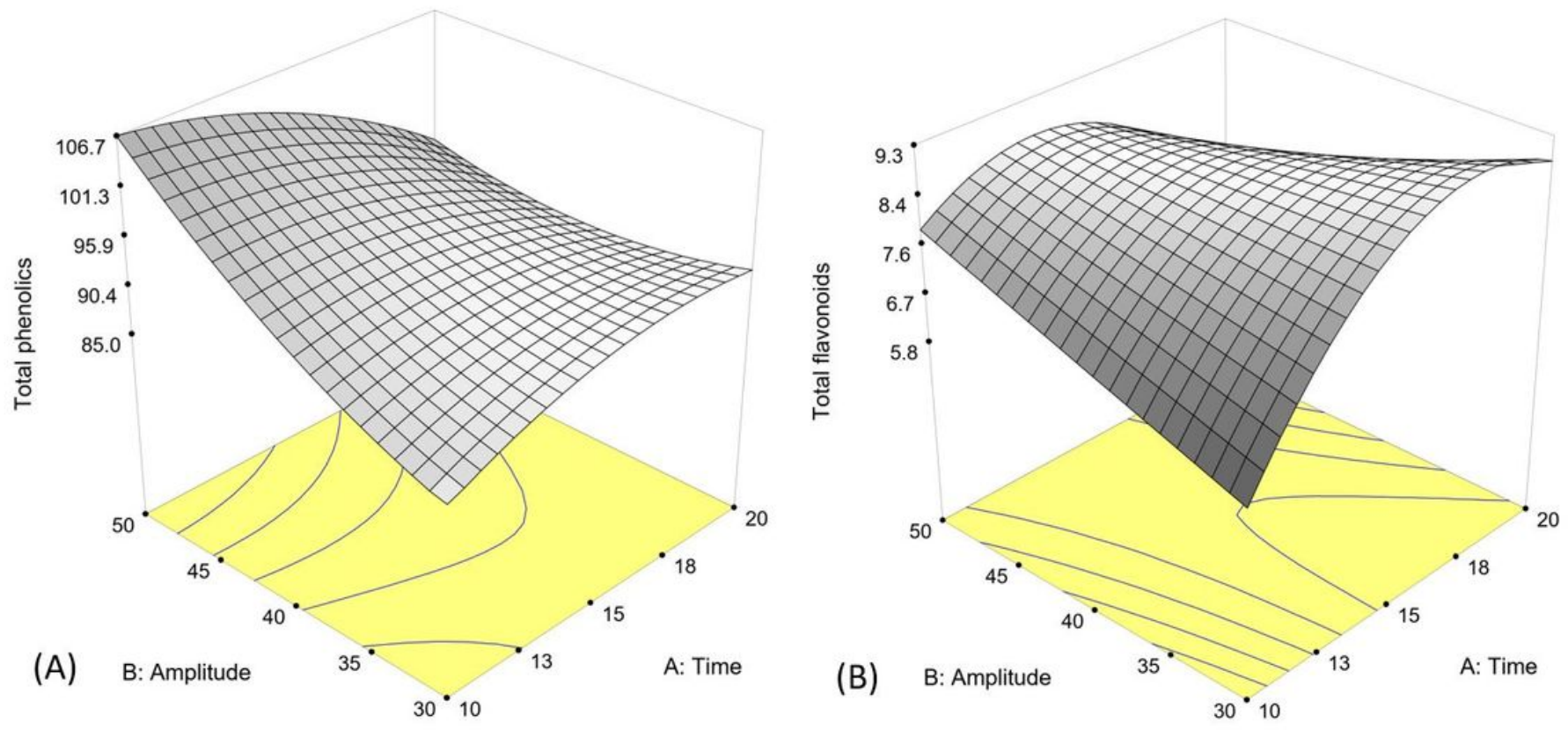

Figure 1

Response surfaces of (A) total phenolic compounds and (B) total flavonoids as a function of UAE time and amplitude.

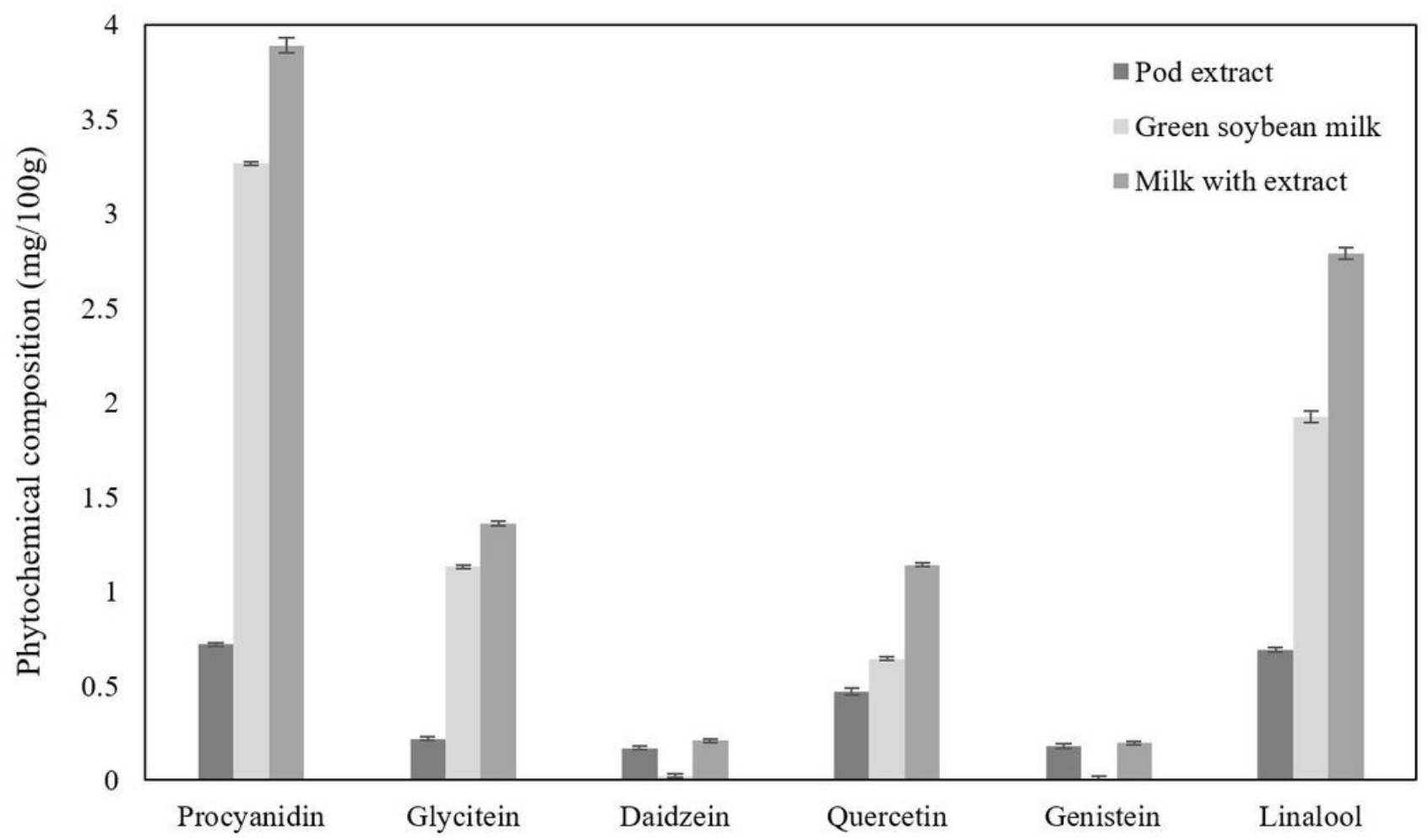

Figure 2 
Phytochemical composition of GSP extracts and green soybean milk 